Chapter 8

\title{
The Relevance of ATR-FTIR Spectroscopy in Semiconductor Photocatalysis
}

\author{
Mohamed Faycal Atitar, Hamza Belhadj, \\ Ralf Dillert and Detlef W. Bahnemann \\ Additional information is available at the end of the chapter
}

http://dx.doi.org/10.5772/60887

\begin{abstract}
Attenuated total reflection Fourier-transform infrared (ATR-FTIR) spectroscopy has a high potential for investigating a wide range of samples and systems. In photocatalysis, various interfacial phenomena can be studied using this technique, including $\mathrm{pH}$-dependent adsorption and photodegradation of probe molecules. The analysis of the processes occurring at the interface of thin particle films deposited on the surface of an ATR crystal, either in the liquid or the gas phase, is perhaps the best way to elucidate the mechanism of adsorption and heterogeneous photocatalytic reactions. This chapter summarizes the recent advances and applications of ATR-FTIR techniques in semiconductor photocatalysis. A brief outlook at some of the possible investigations in this area is provided and the different proposed adsorption and photocatalytic degradation mechanisms are discussed.
\end{abstract}

Keywords: Adsorption, attenuated total reflection Fourier-transform infrared (ATRFTIR), photocatalysis, semiconductor, spectroscopy, thin films, $\mathrm{TiO}_{2}$

\section{Introduction}

The expanding interest in environmental and energy issues led to the consideration of heterogeneous photocatalysis as one of the most promising advanced oxidation processes. The interest in this scientific field has increased in the last decade since photocatalysis is assumed to be a powerful tool for the destruction and remediation of highly toxic pollutants, the 
purification of polluted water and air, the development of self-cleaning surfaces coated with semiconducting metal oxide materials, and the conversion of solar energy into chemical energy [1-3]. Many semiconductor materials have been tested as photocatalysts, nevertheless, due to its low cost, abundance, high activity, and stability under a variety of conditions. Titanium dioxide $\left(\mathrm{TiO}_{2}\right)$ is the most reliable and widely used material $[4,5]$. Accordingly, there has been a tremendous amount of research on diverse aspects of $\mathrm{TiO}_{2}$ (nano)materials, ranging from their synthesis, characterization, and applications to atomic scale, to experimental and theoretical investigations of their fundamental physical and chemical properties [1, 5-7]. Despite these investigations, there remains a need to better understand the reaction mechanisms of the transformation of organic molecules occurring during $\mathrm{TiO}_{2}$ photocatalysis.

Surface science plays a prominent role in mechanistic investigations concerning the photocatalytic process, providing a unique approach to understand bulk, surface, and interfacial phenomena occurring at the $\mathrm{TiO}_{2}$ surface $[6,8,9]$. According to several proposed photocatalytic mechanisms [10, 11], an important point for the conversion of the molecules on $\mathrm{TiO}_{2}$ is the physical and electronic structure of the adsorbed state of the molecules. How a molecule binds onto the $\mathrm{TiO}_{2}$ surface influences its electronic structure, as well as its redox properties. Inter alia, coverage, thermal stability, and reactivity, adsorption structure and site, are all important factors [8]. The interest in surface techniques to investigate liquid-solid and gas-solid interfacial chemistry has grown due to the importance of the information they provide. Few surface spectroscopic techniques are adequate to perform in situ analyses of interfacial interactions. For example, sum-frequency vibrational spectroscopy is restricted to planar solid-solution interfaces [12], infrared ellipsometry is considered mainly as a technique for the analysis of thin solid films rather than of interfacial species [13], and surface enhanced Raman spectroscopy (SERS) requires the presence of metals on the surface. Thus, this complicates the more widespread applicability of SERS [14, 15].

IR spectroscopy is the oldest and most commonly used method for identifying both organic and inorganic chemicals, as well as for providing specific information on molecular structure, chemical bonding, and molecular environment. Being a powerful tool for qualitative and quantitative studies, it can be applied to study solids, liquids, or gaseous samples [16]. Recently, IR spectroscopy has been applied in situ to study surface reactions on immersed solids such as oxides. This has been achieved with particle films via internal reflection or attenuated total reflection (ATR-FTIR) methods. Investigating several metal oxide solid particles in suspensions or deposited as thin films on ATR crystals, these developments have led to in situ ATR-FTIR studies of adsorption and chemical reactions on a variety of solid-liquid and/or solid-gas interfaces in the photocatalysis context [17-24]. The ATR-FTIR technique has proved to be a powerful tool for probing binding mechanisms and for characterizing the adsorption of organic molecules onto metal oxide surfaces in liquid media.

This book chapter focuses on the application of this technique in the above-mentioned context. An overview of the investigations that have been performed to date will be given, analyzing the different experimental procedures, and summarizing the performed investigation of 
surface interactions. An in-depth analysis of the different proposed adsorption and photocatalytic reaction mechanisms on $\mathrm{TiO}_{2}$, as well as on other metal oxides also employed in photocatalysis will be given. To complement this overview, results and interpretations of quantum chemical calculations will also be presented.

\section{History and brief overview of ATR-FTIR spectroscopy}

Infrared absorption spectroscopy (IR) has contributed for more than fifty years to the molecular view on a wide variety of systems. The selection rule for a vibrational mode of a molecule to be IR active is that there is a change of the electric dipole moment of the molecule upon absorption of light. The absorption of infrared light due to the excitation from the ground vibrational energy level to a higher energy level provides information concerning molecular structure and molecular interactions $[15,25,26]$. Due to the existence of the wide absorption spectra database in the mid-infrared region $\left(4000-400 \mathrm{~cm}^{-1}\right)$, infrared spectroscopy is considered as a universal technique since many molecules have strong absorbances in this region [27].

Fourier-transform infrared (FTIR) spectroscopy is a well-established technique based on the idea of the interference of radiation between two beams to yield an interferogram. The latter is a signal produced as a function of the change of path length between the two beams. The two domains of distance and frequency are interconvertible by the mathematical Fourier transformation method.

ATR spectroscopy was introduced simultaneously by Harrik [28] and Fahrenfort [29] based upon the total internal reflection phenomena. In this approach, IR spectra are recorded for a sample material that is in contact with an internal reflection element (IRE). The IR beam is focused onto the edge of the IRE, reflected through the IRE, and then directed to the detector (cf. Figure 1) [26, 27]. In this case, all the light reflects off the internal surface of the IRE, hence explaining the term total internal reflection [27]. The internal reflection element (IRE) or ATR crystal has, in most cases, a higher refractive index $\left(n_{1}\right)$ as compared to the sample $\left(n_{2}\right)$. Another important parameter is the incidence angle $\theta$ that can be determined from the refractive indexes of the sample $\left(n_{2}\right)$ and the IRE $\left(n_{1}\right)$ :

$$
\theta=\sin ^{-1}\left(\frac{n_{2}}{n_{1}}\right)
$$

The major applications of the ATR method are in the mid-IR region. However, the range has been extended to the near-IR, the far-IR, as well as to the UV and visible spectral regions. Therefore, it is of great importance to choose a suitable ATR crystal for a given application. The most common ATR crystals with their respective refractive indexes and some other relevant properties are summarized in Table 1. 


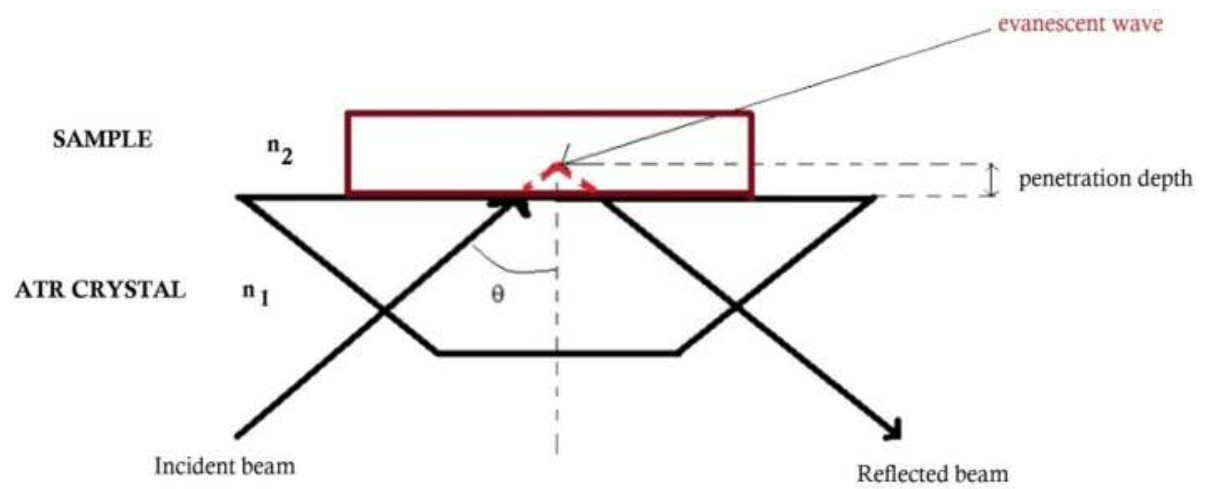

Figure 1. Schematic diagram of a horizontal ATR sampling accessory illustrating the important parameters [16].

\begin{tabular}{lllll}
\hline Material & $\begin{array}{l}\text { Refractive } \\
\text { index }\end{array}$ & $\begin{array}{l}\text { Wavenumber } \\
\text { range }\left(\mathbf{c m}^{-1}\right)\end{array}$ & $\mathrm{d}_{\mathrm{p}}(\mu \mathrm{m})$ & References \\
\hline Diamond & 2.4 & $45000-2500$ & $1.35-1.66$ & {$[30][31][32]$} \\
Germanium $(\mathrm{Ge})$ & 4 & $5500-870$ & $0.65-0.73$ & {$[30][31][32]$} \\
Zinc Selenide $(\mathrm{ZnSe})$ & 2.41 & $20000-650$ & $1.22-1.66$ & {$[30][31][32]$} \\
AMTIR (As/Ge/Se glass) & 2.5 & $11000-750$ & 1.46 & {$[30]$} \\
Silicon (Si) & 3.4 & - & $0.84-1.17$ & {$[30][32]$} \\
Thallium bromoiodide (KRS-5) & 2.37 & $20000-250$ & $1.22-1.73$ & {$[30][32]$} \\
Cd telluride $(\mathrm{CdTe})$ & 2.67 & $10000-450$ & - & {$[31]$} \\
Saphire (Al $\left.\mathrm{O}_{3}\right)$ & 1.74 & $25000-1800$ & - & {$[31]$} \\
Zinc Sulfide $(\mathrm{ZnS})$ & 2.2 & $17000-950$ & 2.34 & {$[31][32]$} \\
Cubic Zirconia $\left(\mathrm{ZrO}_{2}\right)$ & 2.15 & $25000-1800$ & - & {$[31]$} \\
\hline
\end{tabular}

Table 1. Relevant properties of some common ATR crystals.

Since the IR beam should penetrate the sample, the penetration depth $\left(d_{p}\right)$ is one of the important parameters in ATR-FTIR spectroscopy. The measure of the depth that the infrared beam enters into the sample is defined by equation (2):

$$
d_{p}=\frac{1}{\left[2 \pi W n_{1}\left(\sin ^{2} \theta-n_{21}^{2}\right)^{\frac{1}{2}}\right]}
$$

where $d_{p}$ is the depth of penetration, $W$ the wavenumber, $n_{1}$ the refractive index of the ATR crystal, $\theta$ the angle of incidence, and $n_{21}$ the fraction $\frac{n_{2}}{n_{1}}$.

Each of the parameters mentioned above has important messages to teach us about the ATR technique and its application. Readers interested in details of the theory of ATR should consult the respective literature [16, 25, 27]. 


\section{Experimental processing}

One of the advantages of the ATR-FTIR technique is that an experiment can be easily conducted to study the interactions between a chosen probe molecule and the surface of different metal oxides. The whole procedure consists in the preparation of a thin film of nanoparticles of the chosen metal oxide on the ATR crystal. This thin film should be stable, at least during the experiment, and its thickness should allow the penetration of the IR beam to reach the interface, e.g., the sample solution above the oxide layer. A thin homogeneous layer of the nanoparticles on the ATR crystal is generally produced from their suspension in an adequate solvent. This suspension is carefully drop-casted on the IRE material. Examples of the preparation of these thin layers, especially those made of $\mathrm{TiO}_{2}$, can be found elsewhere $[18,19,23,33]$.

It is worth noting that the contact between the probe molecule and the layer can lead to a change in some operational parameters such as $\mathrm{pH}$, temperature, and ionic strength of the supernatant solution. Therefore, studies on adsorption phenomena are better carried out employing flow cell reactors either in the liquid or the gas phase (see Figure 2a) where the solution or the dispersant circulate continuously over the layer. This allows the control of the above-mentioned parameters and the monitoring of the evolution in time of the system under different conditions. As an alternative, a sample batch system can also be employed where the inlet and outlet are closed (Figure 2b) [23].

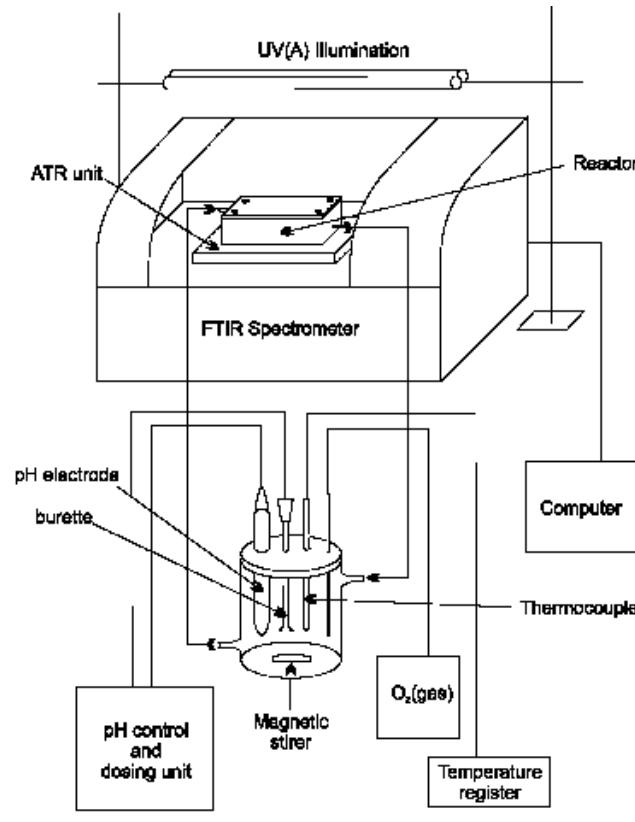

(a) Set-up
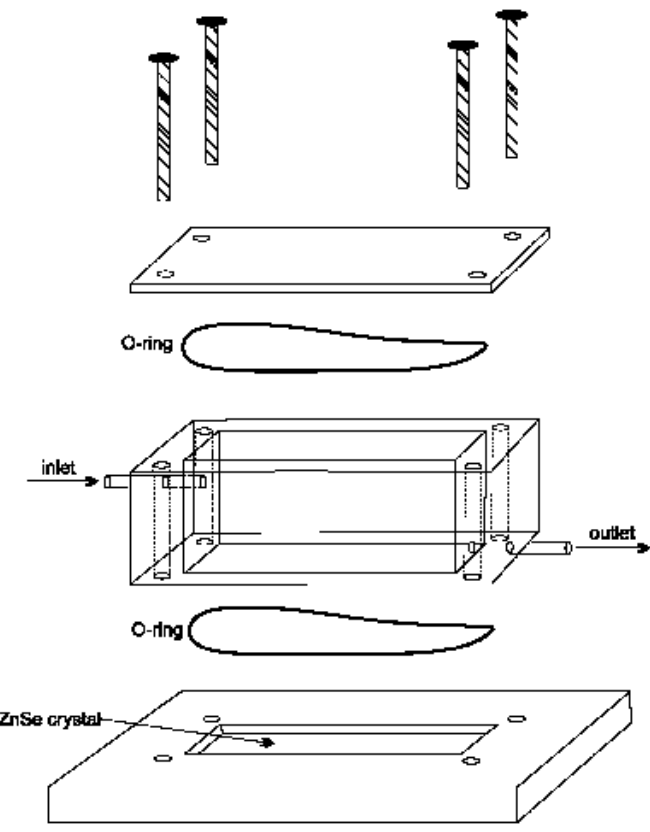

(b) Detall of the ATR unt and reactor

Figure 2. Flow cell reactor for ATR-FTIR spectroscopic studies (Reproduced from [23] with permission of the PCCP Owner Societies). 
Prior to coating the ATR crystal, a spectrum of the blank ATR crystal is collected for spectral processing. Mainly, two different approaches can be used for the spectral processing. The first one is the normalization of the spectra of the ligand to that of the matrix (solvent at the $\mathrm{pH}$ of interest in the liquid phase or dispersant in the gas phase) from which a spectrum is collected. The probe molecule is then introduced and the corresponding spectrum is collected. The spectrum of the probe molecule is then referenced to the background spectrum (solvent/ dispersant). The second approach is as follows: after preparing the thin film, a spectrum of the solvent at the $\mathrm{pH}$ of interest (or of the dispersant in the gas phase) is collected; the probe molecule is introduced and a spectrum is collected; the single beam spectrum of both solvent/ dispersant and of the probe molecule in the solvent/dispersant is referenced to the blank ATR crystal to obtain the absorbance spectra of each. Subsequently, the absorbance spectrum of the solvent/dispersant is subtracted from the spectrum of the probe molecule. To collect spectra for the probe molecule alone the same experimental process is used but without the nanoparticle thin layer [30].

\section{Probing interfacial reactions by ATR-FTIR investigations}

\subsection{Metal oxide-water interface}

Considering its relevance to semiconductor photocatalysis, water splitting, and other important applications, the interaction of water with metal oxide surfaces, especially $\mathrm{TiO}_{2}$, has been the focus of several experimental and theoretical investigations over the last decades $[3,4,6$, 8, 34-36]. Molecular, dissociated, and undissociated states of water adsorbed at a solid surface have been suggested. In addition to that, a mixture of these adsorption states is possible.

ATR-FTIR spectroscopy is one of the suitable techniques to investigate the adsorption of water molecules on a metal oxide surface under a wide range of conditions [37-39]. From many perspectives, numerous experimental and theoretical water adsorption studies have been conducted by means of ATR-FTIR spectroscopy [17, 37, 40, 41].

Figure 3 depicts the typical spectra of water adsorbed on $\mathrm{TiO}_{2}$ (anatase/rutile Evonik-Degussa Aeroxide $\mathrm{TiO}_{2}$ P25) [38]. The broad absorption band at around $3600-2800 \mathrm{~cm}^{-1}$ and the small peak at $3696 \mathrm{~cm}^{-1}$ are well-known to be the stretching vibration modes of the $\mathrm{H}_{2} \mathrm{O}$ molecules, which have complex interactions through hydrogen bonds, and the end part of polymerically chained $\mathrm{H}_{2} \mathrm{O}$ molecules without hydrogen bonds, respectively. The broad band contains not only the components of the $\mathrm{H}_{2} \mathrm{O}$ molecules with different numbers of hydrogen bonds but also the Fermi resonance attributed to the overtone absorption of the bending mode $\delta\left(\mathrm{H}_{2} \mathrm{O}\right)$ at 1637 $\mathrm{cm}^{-1}$. Therefore, it is difficult to analyze the detailed adsorption state of the polymerically chained $\mathrm{H}_{2} \mathrm{O}$ molecules on metal oxide surfaces only from FTIR (mid-infrared) measurements [38]. However, based on the information obtained from such IR spectra, ATR-FTIR spectroscopy has been used for the characterization and identification of intermediate mechanisms involved in environmental interfaces [42], mainly during photocatalytic oxidation processes induced at the $\mathrm{TiO}_{2}$-water interface $[37,40]$. 


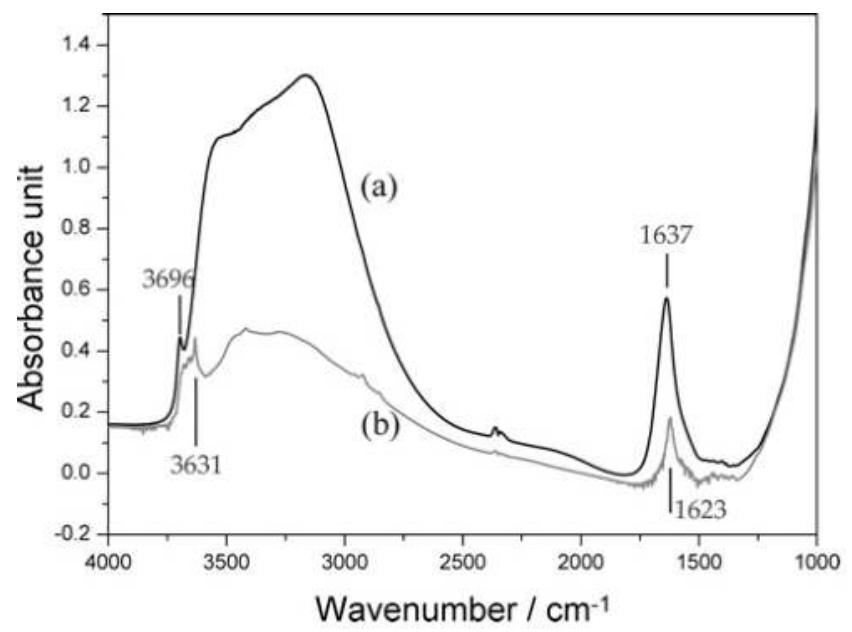

Figure 3. FT-IR (MIR) absorption spectra of $\mathrm{TiO}_{2}$ (Evonik-Degussa Aeroxide $\mathrm{TiO}_{2} \mathrm{P} 25$ ) in air (a) and after evacuation at room temperature for $1 \mathrm{~h} \mathrm{(b)} \mathrm{(Reprinted} \mathrm{with} \mathrm{permission} \mathrm{from} \mathrm{Takeuchi} \mathrm{M,} \mathrm{Martra} \mathrm{G,} \mathrm{Coluccia} \mathrm{S,} \mathrm{Anpo} \mathrm{M.} \mathrm{Investiga-}$ tions of the Structure of $\mathrm{H}_{2} \mathrm{O}$ Clusters Adsorbed on $\mathrm{TiO}_{2}$ Surfaces by Near-Infrared Absorption Spectroscopy. Journal of Physical Chemistry B; 109(15):7387-91. Copyright (2005) American Chemical Society).

Starting from the hypothesis that adsorbed $\mathrm{H}_{2} \mathrm{O}$ changes its conformation due to the coadsorption of cyclohexane on $\mathrm{TiO}_{2}$ (anatase, Sachtleben Hombikat UV100), Almeida et al. [40] have shown with the help of additional DFT (Density Functional Theory) calculations, yielding the adsorption energy and the structure of the water molecule at different hydration levels (Figure 4), that at least three layers of water are formed during the adsorption process. The first layer includes only chemisorbed $\mathrm{H}_{2} \mathrm{O}$ molecules. The second hydration level includes physisorbed (H-bonded) $\mathrm{H}_{2} \mathrm{O}$ molecules on surface $\mathrm{OH}$ sites, and the highest hydration level contains an additional adsorbed water layer. The dissociative chemisorption of water is assumed to be energetically favored. In addition to that, dissociative chemisorption of water generates at least two different $\mathrm{Ti}-\mathrm{OH}$ groups. At least one of these two new $\mathrm{OH}$ sites contains an oxygen atom originally originating from the $\mathrm{TiO}_{2}$ lattice structure [40]. This finding allowed the authors to provide a spectral and structural interpretation of the mode of adsorption of cyclohexanone on the hydrated $\mathrm{TiO}_{2}$ surface [40].

Besides of that, several research reports have identified and specified the different bending modes and structures of water on the $\mathrm{TiO}_{2}$ surface during, before, and after UV light irradiation. It has been reported that UV irradiation induces a structural ordering of the adsorbed water layer [43], or results in an increase in the amount of surface $\mathrm{OH}$ groups, thus increasing the hydrophilicity of the $\mathrm{TiO}_{2}$ surface [44]. Mendive et al. [37] have revealed by ATR-FTIR studies that the disaggregation of particle agglomerates plays an important role in UV illuminated aqueous $\mathrm{TiO}_{2}$ nanoparticulate systems.

However, it should be noted here that the exact nature of the adsorption of water is still a matter of discussion in the field of metal oxide (especially of $\mathrm{TiO}_{2}$ ) photocatalysis. This is a 


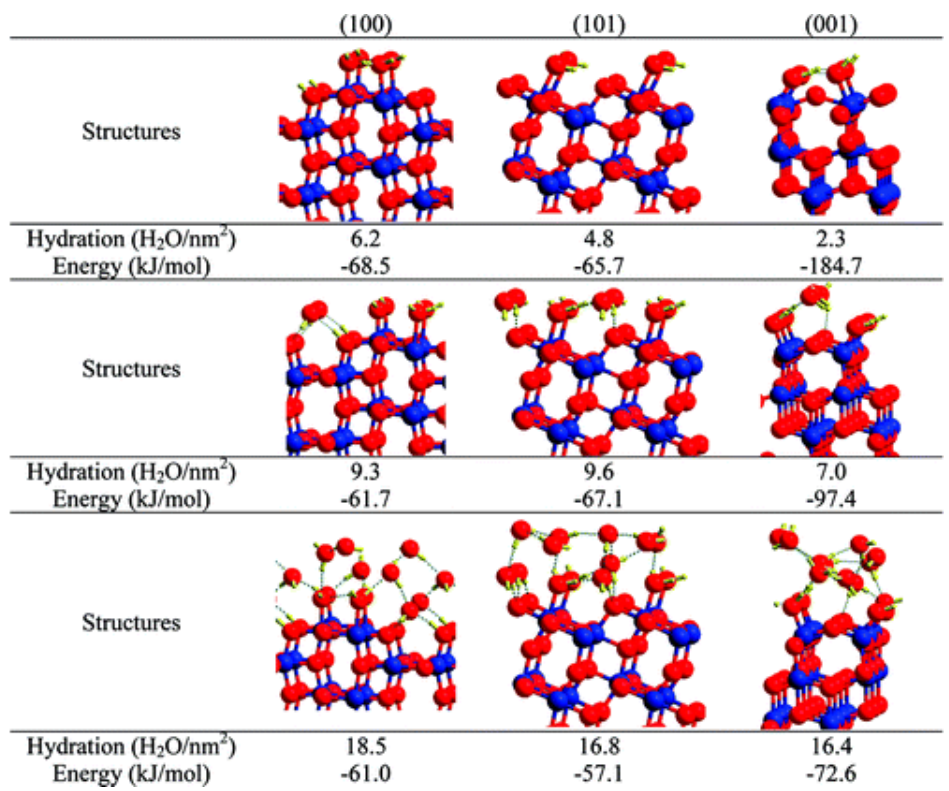

Figure 4. Adsorption energies and structures of $\mathrm{H}_{2} \mathrm{O}$ on $\mathrm{TiO}_{2}(100)$, (101), and (001) facets, at different hydration levels (Reprinted with permission from Almeida A, Calatayud M. Combined ATR-FTIR and DFT Study of Cyclohexanone Adsorption on Hydrated $\mathrm{TiO}_{2}$ Anatase Surfaces. Journal of Physical Chemistry C; 115(29):14164-14172. Copyright (2011) American Chemical Society).

consequence of the diverse possibilities of interpretation arising from the combination of experimental results obtained by ATR-FTIR spectroscopy and by other techniques. Obviously, there is not yet a general consensus on the mechanism of adsorption of water on $\mathrm{TiO}_{2}$.

\subsection{Interactions of probe molecules with the metal oxide surface}

ATR-FTIR spectroscopy yields important insight into the surface speciation of probe molecules adsorbed on nanomaterials [30]. Chemical or inner sphere adsorption is generally studied when it is expected that the probe molecule is able to coordinate with the metal ions of the substrate covering the ATR crystal [15].

Investigations of the interaction of a large number of ligands on metal oxide, metal hydroxide, and metal oxyhydroxide systems have been performed employing ATR-FTIR spectroscopy [26]. The objective of these investigations is to obtain an insight into the chemical nature of these interactions, being either qualitative such as the mode of adsorption and the surface speciation, or quantitative such as the kinetics and the surface coverage.

It is worth to note that $\mathrm{TiO}_{2}$ nanoparticles are much more extensively used as substrates as compared with other metal oxides. The adsorption of organic compounds bearing common functional groups such as acids [23, 45, 46], amino acids [47], phenolic compounds [11, 48], and a few complex heteroaromatic compounds [49-52] has been studied in detail (cf. Table 3). 
As an example, a typical ATR-FTIR spectrum of an aqueous solution of the herbicide imazapyr in the absence and presence of a $\mathrm{TiO}_{2}$ layer is presented in Figure 5. The reliability of information obtained from the IR spectra is dependent mainly upon the correct assignment of the vibrational modes by comparison with published spectroscopic data [15, 30]. Mudunkotuwa et al. have presented a summary of several common IR absorption band frequencies (Table 2) [30]. Furthermore, the infrared spectral data collected for coordination compounds [53] are very useful when interpreting the spectra of adsorbates, which mostly resemble those of ligands of coordination compounds [15]. In addition to that, the interpretation of the increase in the intensities of the bands of functional groups, as well as the shifting of these bands either to the blue or to the red spectral regions also provide important information concerning the type of interaction between adsorbate and surface. The interpretation of IR bands is very helpful for a qualitative analysis, e.g., concerning the points of interactions, the modes of adsorption, and the molecular speciation, respectively.

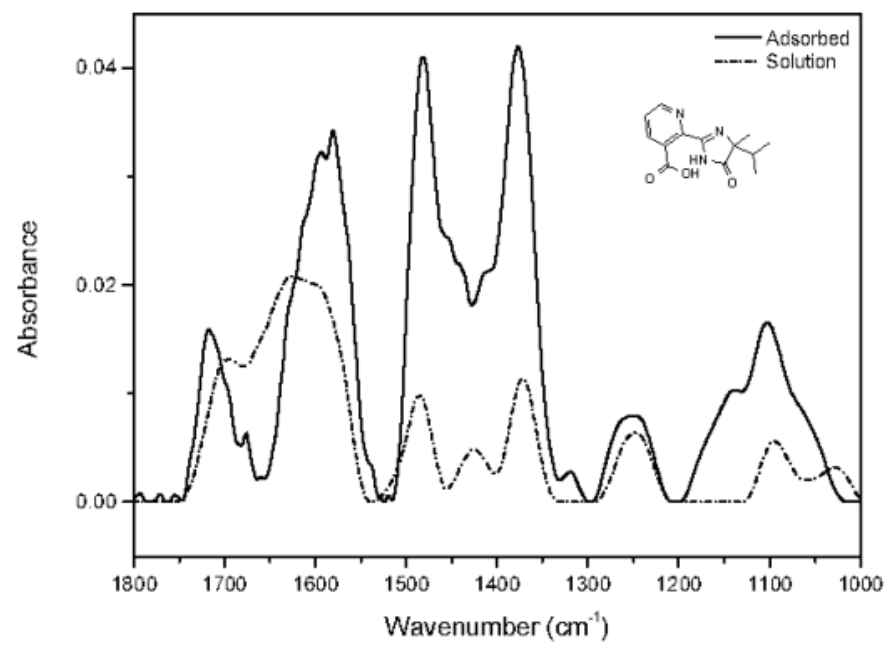

Figure 5. ATR-FTIR spectra of $8 \times 10^{-3} \mathrm{~mol} \mathrm{~L}^{-1}$ imazapyr aqueous solution at $\mathrm{pH} 3$ (dashed lines); and $2 \times 10^{-3} \mathrm{~mol} \mathrm{~L}^{-1}$ imazapyr aqueous solution in contact with $\mathrm{a} \mathrm{TiO}_{2}$ film (solid lines). Reference spectra were of water in contact with the bare $\mathrm{ZnSe}$ prism and of the bare $\mathrm{TiO}_{2}$ film respectively [54].

As mentioned above, the complexity of the obtained IR spectra usually requires the combination of different techniques to enable their interpretation. Generally, the deductions resulting from the analysis of the IR spectra have to be supported by the results of other experimental techniques and/or by theoretical calculations. Several experimental and theoretical studies on the adsorption of aliphatic mono- and di-carboxylic acids on metal oxide surfaces have been performed [46]. It is assumed that the binding of carboxylates at the solid metal oxide surface occurs in several ways such as physisorption through electrostatic attraction and hydrogen bonding, and chemisorption in different modes including monodentate, bridged bidentate, and chelating bidentate adsorbed structures [55-57]. These different binding modes can be 


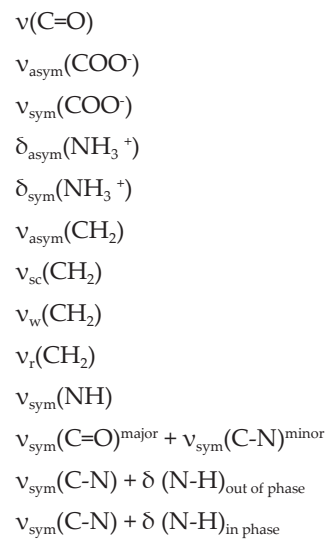

1730-1720

1620-1590

1410-1390

1630

1571

2920

$1442-1438$

1400-1200

$730-720$

3300-3100

1700-1600 (Amide I)

1580-1510 (Amide II)

1400-1200 (Amide III)

Table 2. IR absorption frequencies of common organic functional groups (Adapted from [30] with permission of The Royal Society of Chemistry).

distinguished in an infrared spectrum by the difference $\Delta v_{\mathrm{a}-\mathrm{s}}$ of the frequencies of the asymmetric and the symmetric mode of the carboxylate stretching vibration. By comparing the $\Delta v_{\mathrm{a}-\mathrm{s}}$ of free aqueous carboxylate, $\Delta v_{\mathrm{a}-\mathrm{s}}$ (free), to the $\Delta v_{\mathrm{a}-\mathrm{s}}$ (adsorbed) values measured in transition metal complexes, the following correlations were found $[46,56,58]$ :

$\Delta v_{\text {a-s }}($ adsorbed $)>\Delta v_{\text {a-s }}$ (free): monodentate coordination

$\Delta v_{\mathrm{a}-\mathrm{s}}($ adsorbed $)<\Delta v_{\mathrm{a}-\mathrm{s}}($ free): bidentate chelating or bridging

$\Delta v_{\mathrm{a}-\mathrm{s}}$ (adsorbed) $\ll<\Delta v_{\mathrm{a}-\mathrm{s}}$ (free): bidentate chelating, unless short metal-metal bonds are present

DFT calculations have been performed by Vittadini et al. for several possible adsorption conformations of formic acid and sodium formate on the anatase surface to support the interpretation of ATR-FTIR spectra measured of formic acid adsorbed on the $\mathrm{TiO}_{2}$ surface [59]. The comparison of the calculated results with this experimental information enabled the identification of seven different surface species (see Figure 6). On the hydrated surface, both $\mathrm{HCOOH}$ and $\mathrm{HCOONa}$ preferentially form inner-sphere adsorption complexes. $\mathrm{HCOOH}$ as monodentate adsorbate dissociates due to the interaction with a nearby water molecule, while HCOONa prefers a bridging bidentate structure [59].

Mono-carboxylic acids, i.e., formic and acetic acid, were found to bind on $\mathrm{ZrO}_{2}$ and $\mathrm{Ta}_{2} \mathrm{O}_{5}$ surfaces in both protonated and deprotonated carboxylic acid forms indicating a bridging bidentate adsorption. Under the experimental conditions of this work no adsorption of formic acid onto $\mathrm{TiO}_{2}$ and $\mathrm{Al}_{2} \mathrm{O}_{3}$ was observed [46]. 
molecular adsorption<smiles>OCO</smiles>

$\mathrm{MHa}$ monodentate through $\mathrm{CO}$<smiles>[13CH3]OC=O</smiles>

$\mathrm{MHb}$

monodentate through $\mathrm{OH}$<smiles>C1COO1</smiles>

$\mathrm{BH}$<smiles>OCO[Tl]</smiles>

BBH

dissociative adsorption<smiles>O=CO[Tl]</smiles>

$M(H)$ ester-type<smiles>C1=[In]OCO1</smiles>

$\mathrm{B}(\mathrm{H})$ bidentate chelating<smiles>O=CO[Tl]</smiles>

$\mathrm{BB}(\mathrm{H})$

bidentate bridging

Figure 6. Possible configurations for $\mathrm{HCOOH}$ and $\mathrm{HCOO}^{-}$species bound to metal cations (Reprinted with permission from Vittadini A, Selloni A, Rotzinger FP, Grätzel M. Formic Acid Adsorption on Dry and Hydrated $\mathrm{TiO}_{2} \mathrm{Anatase}$ (101) Surfaces by DFT Calculations. Journal of Physical Chemistry B; 104(101):1300-1306. Copyright (2000) American Chemical Society).

Dicarboxylic acids adsorb much more strongly to oxide surfaces than mono-carboxylic acids due to both electrostatic and chemical interactions.

Oxalic acid is one of the most investigated molecules in this regard [18, 45, 58, 60, 61]. Based on a series of spectra recorded at varying different experimental parameters (concentration, $\mathrm{pH}$, and ionic strength), and supported by the comparison of these spectra with those of the aqueous $\left[\mathrm{Fe}(\mathrm{Ox})_{\mathrm{y}}\right]_{\mathrm{z}}$ complex, Hug et al. [18] described several surface complexes formed during the adsorption of oxalic acid at the $\mathrm{TiO}_{2} \mathrm{P} 25$ surface. The obtained data strongly support the assumption that oxalate forms specific inner-sphere coordination complexes with surface $\mathrm{Ti}^{4+}$ sites. These complexes are formed through bidentate bridging or monodentate bending modes.

Mendive et al. have published several papers presenting experimental results of their investigation of the $\mathrm{TiO}_{2}$-oxalic acid system using both pure anatase and rutile phases. In addition to that, data of quantum chemical calculations using Modified Symmetrically Orthogonalized 
Intermediate Neglect of Differential Overlap (MSINDO) have been presented to yield a complete insight into the $\mathrm{TiO}_{2}$-oxalate system [23, 24, 62, 63]. A detailed analysis of the experimental ATR-FTIR data and the data obtained from theoretical calculations (IR spectra (Figure 7) and calculated bending energies) has led to the suggestion of different adsorbate structures of oxalic acid either on anatase or on rutile nanoparticles (Figure 8). By comparison between both $\mathrm{TiO}_{2}$ phases (anatase and rutile), the difference as well as the similarity in the adsorption of oxalate can be explained either by the mode of adsorption, the structure of the surface complexes, the surface speciation of either $\mathrm{TiO}_{2}$ phases, or the adsorption energies.

Young et al. [45] have published the results of an ATR-FTIR study focused on the adsorptiondesorption kinetics of oxalic acid on the anatase $\mathrm{TiO}_{2}$ surface. The measured spectra were not found to be well resolved. However, based on the absorbance versus time behavior, the authors were able to extract the pseudo-first-order rate constants corresponding to the three expected adsorbed species of oxalic acid at the $\mathrm{TiO}_{2}$ surface.

Furthermore, Mendive et al. [61] have proposed the mechanism of the photocatalytic degradation of oxalic acid with the help of the above mentioned experimental and theoretical investigations [24, 63]. The possible pathways for the formation of oxalic acid photoproducts, as well as the role of the $\mathrm{TiO}_{2}$ surface as active surface have been discussed in detail [61]. An example of the proposed degradation pathways of the oxalic acid surface complexes is depicted in Figure 9.
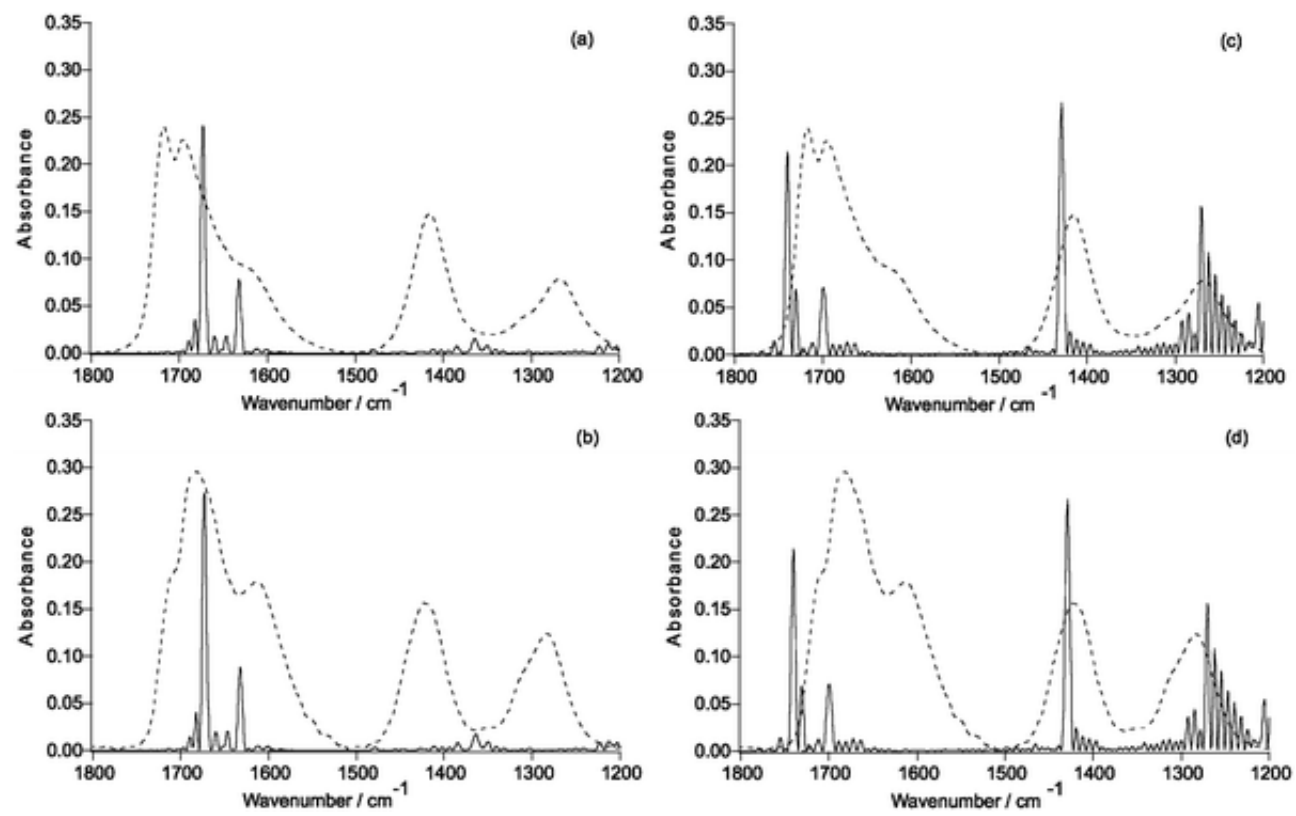

Figure 7. Experimental and calculated FTIR spectra of oxalic acid on anatase (Reproduced from [23] with permission of the PCCP Owner Societies). 

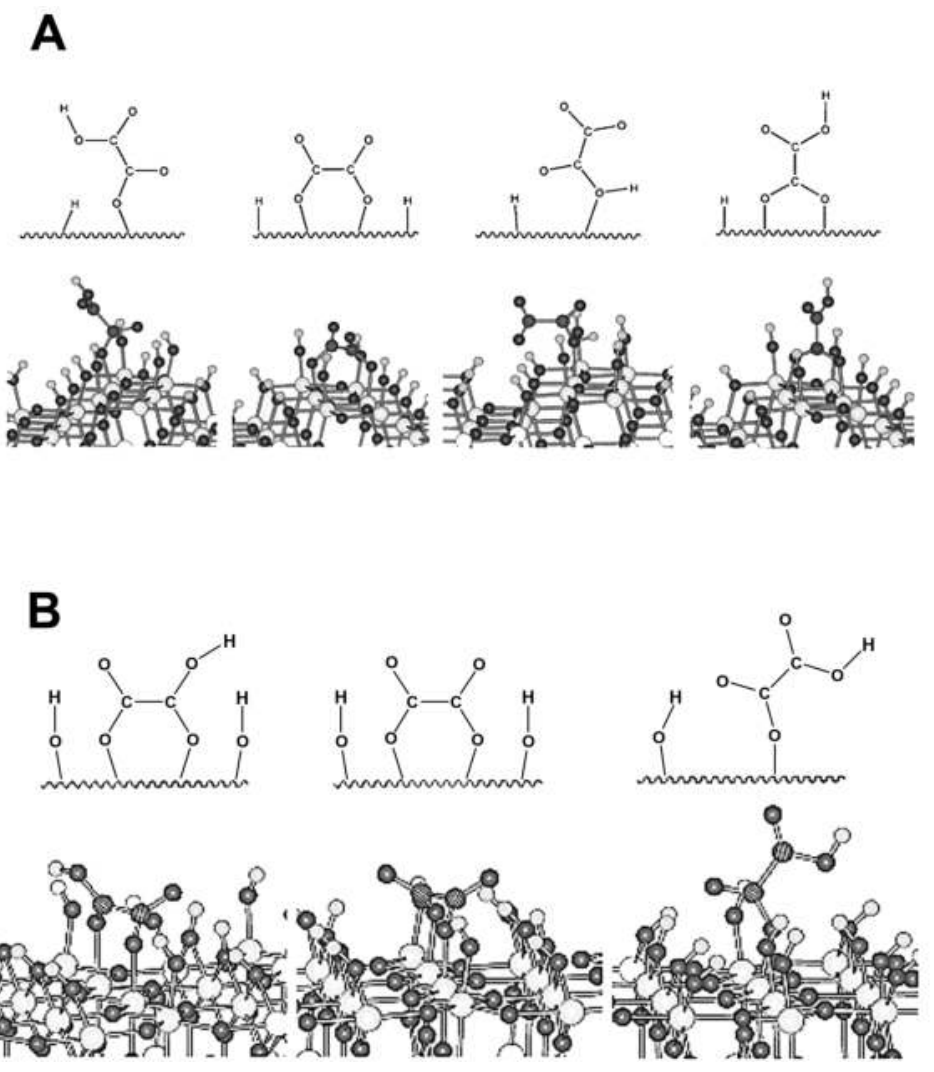

Figure 8. Adsorbed structures of oxalic acid on anatase (A) (Reproduced from [24] with permission of the PCCP Owner Societies) and Rutile (B) (Reproduced from [63] with permission of the PCCP owner Societies) in equilibrium in the dark. A scheme of every structure is provided. Ti, O, H and C atoms are represented by large light, dark, small light and dark-dashed spheres respectively.

As mentioned in the introduction of this chapter, the direct evidence for the formation of structurally different surface complexes is an important step in the understanding of metal oxide photocatalysis, especially of $\mathrm{TiO}_{2}$ photocatalysis. This is due to the fact that the reactivity and the pathways for product formation are determined by the structures of the formed surface species during the dark adsorption. Recently, Montoya et al. [11] have investigated the interaction of the $\mathrm{TiO}_{2}$ surface with three probe molecules, e.g., formic acid, benzene, and phenol employing ATR-FTIR spectroscopy. Based upon the analysis of the IR spectra (Figure 10 ), assumptions have been made concerning the physisorption of benzene (no changes have been observed in the spectra with and without the $\mathrm{TiO}_{2}$ layer), the strong chemisorption of formic acid, and also the role of the solvent (water or acetonitrile) for the adsorption mode of phenol. Based on these results, the authors provided an insight into the mode of interaction of the probe molecules with the $\mathrm{TiO}_{2}$ surface (chemisorption or physisorption) (Figure 11). In addition to that, they discussed the photocatalytic oxidation mechanism induced either by the 


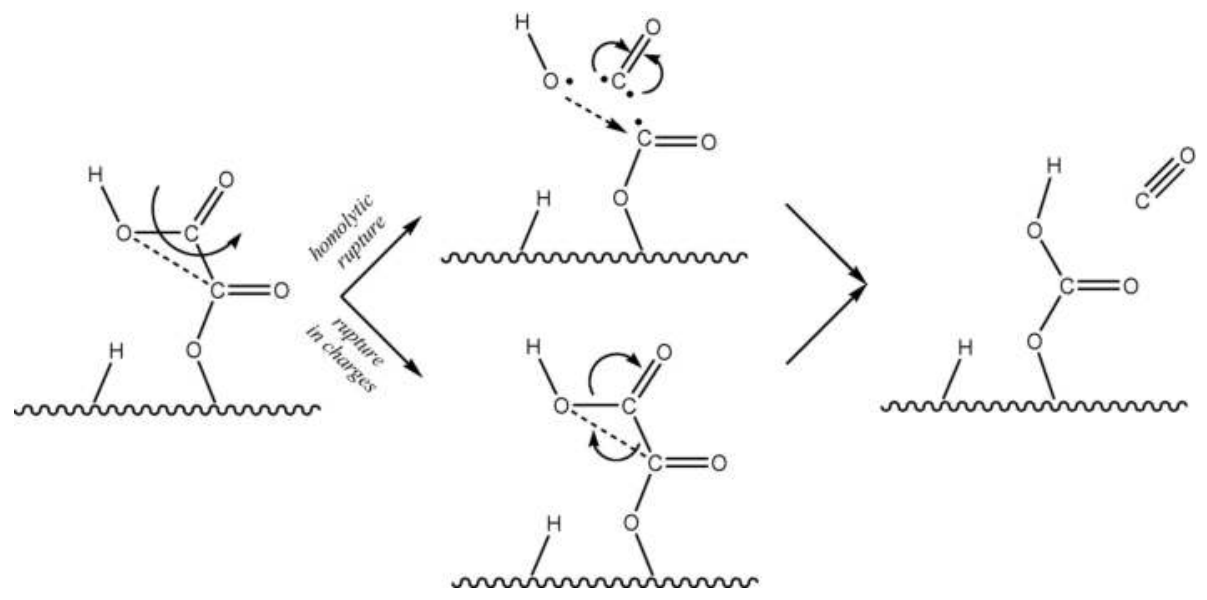

Figure 9. Possible photocatalytic degradation pathways of species adsorbed on anatase (Reprinted from Oxalic Acid at the $\mathrm{TiO}_{2} /$ Water Interface under UV(A) Illumination: Surface Reaction Mechanisms, Cecilia B. Mendive, Thomas Bredow, Jenny Schneider, Miguel Blesa, Detlef Bahnemann. Journal of Catalysis 2015, 322:60-72, Copyright (2015), with permission from Elsevier).

reaction of surface trapped holes with the adsorbate (direct pathway) or the reaction of photocatalytically generated ${ }^{\circ} \mathrm{OH}$ radicals with the physisorbed molecules (indirect pathway). The authors concluded that formic acid is directly oxidized due to its strong chemisorption onto the $\mathrm{TiO}_{2}$ surface, while physisorbed benzene is indirectly oxidized. For phenol the authors suggested a combination of both pathways [10,11].

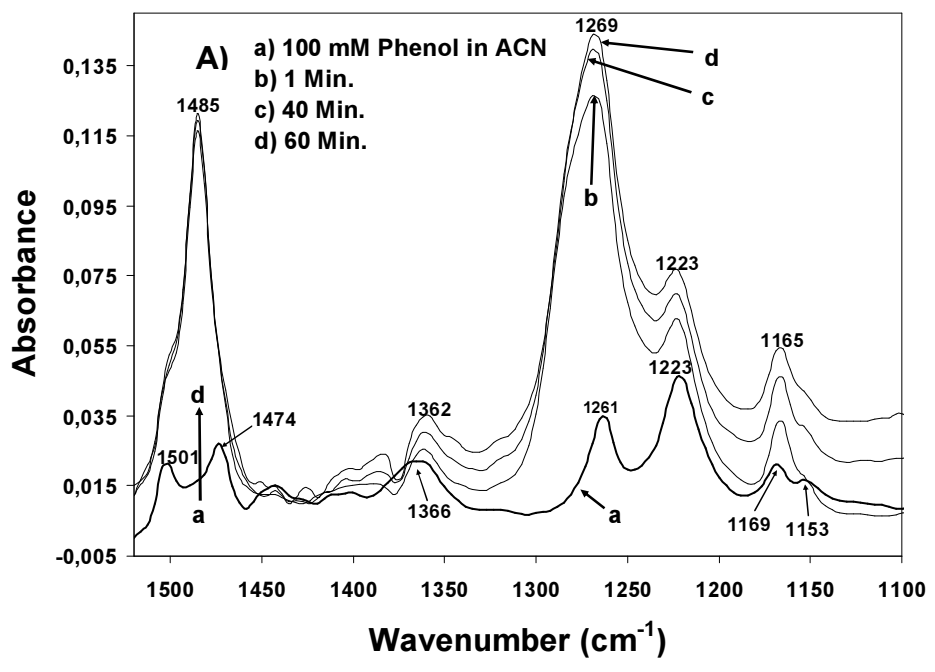



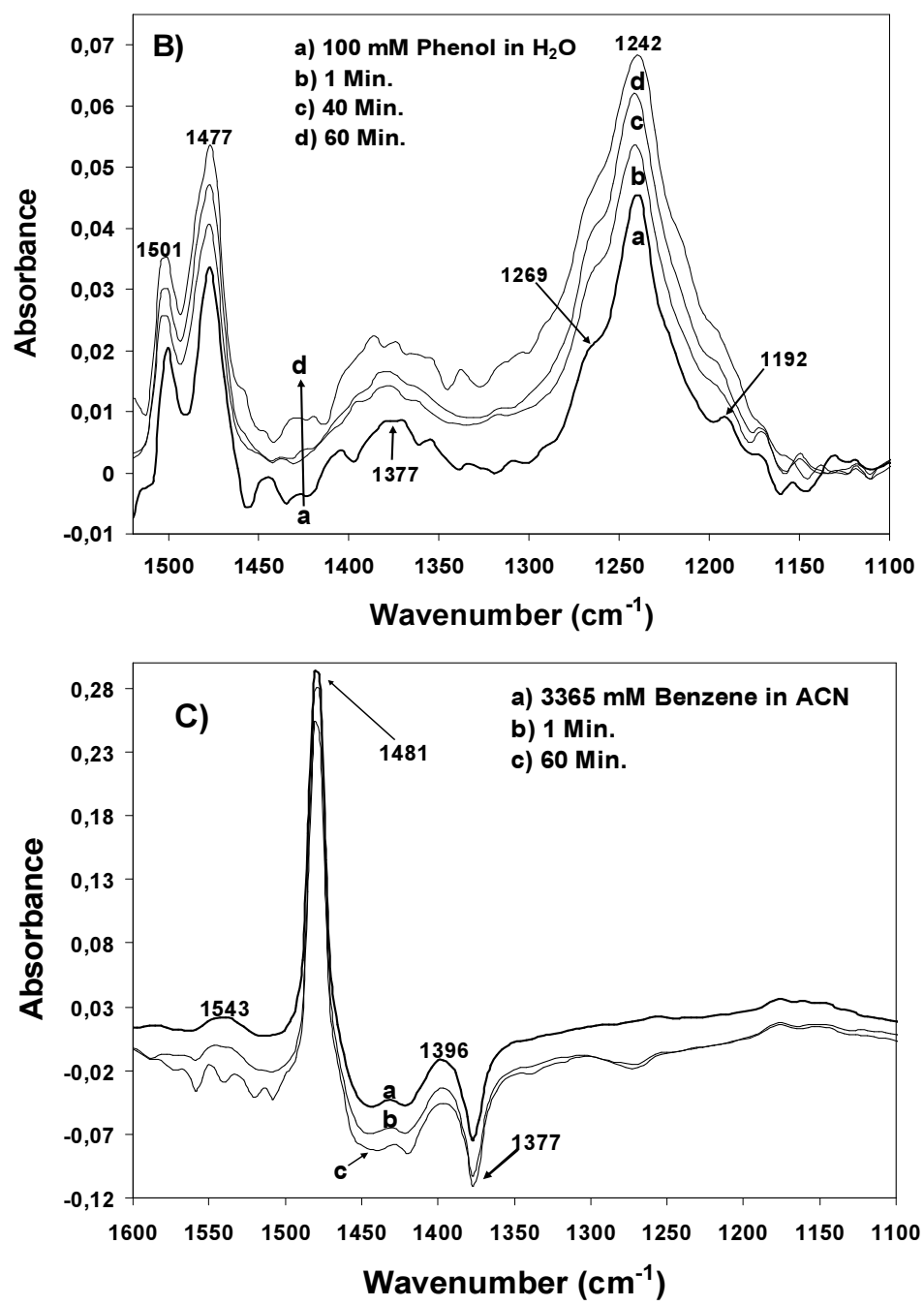

Figure 10. ATR-FTIR spectra of: A) a $100 \mathrm{mM}$ solution of acetonitrile dissolved phenol, in the absence (a) and in the presence of an anatase film under different $\mathrm{TiO}_{2}$-Phenol contact times (b-d); $\mathrm{B}$ ) a $100 \mathrm{mM}$ solution of water dissolved phenol ( $\mathrm{pH} 3$ ) in the absence (a) and in the presence of a $\mathrm{TiO}_{2}$ anatase film, under different $\mathrm{TiO}_{2}-\mathrm{Phenol}$ contact times (b-d); C) a $3365 \mathrm{mM}$ solution of acetonitrile dissolved benzene in absence (a) and presence of a $\mathrm{TiO}_{2}$ anatase film under different $\mathrm{TiO}_{2}$-Benzene contact times (b-c) (Reprinted with permission from Montoya JF, Atitar FM, Bahnemann DW, Peral J, Salvador P. Comprehensive Kinetic and Mechanistic Analysis of $\mathrm{TiO}_{2}$ Photocatalytic Reactions According to the Direct-Indirect (DI) Model: II) Experimental Validation. Journal of Physical Chemistry C; 28(118):14276-14290. Copyright (2014) American Chemical Society).

In addition to the presented examples, several experimental and theoretical studies have been performed concerning the adsorption and various photocatalytic reactions by means of the ATR-FTIR technique. Table 3 presents a survey of published data on the adsorption as well as 

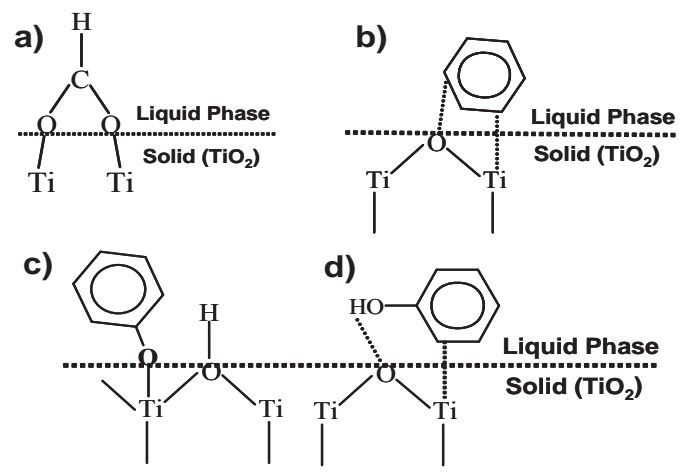

Figure 11. Interaction modes of benzene, formic acid and phenol, model organic compounds with the $\mathrm{TiO}_{2}$ surface $(\mathrm{Re}-$ printed with permission from Montoya JF, Atitar FM, Bahnemann DW, Peral J, Salvador P. Comprehensive Kinetic and Mechanistic Analysis of $\mathrm{TiO}_{2}$ Photocatalytic Reactions According to the Direct-Indirect (DI) Model: II) Experimental Validation. Journal of Physical Chemistry C; 28(118):14276-90. Copyright (2014) American Chemical Society).

the photooxidation of aqueous organic compounds on metal oxide surfaces studied by means of ATR-FTIR spectroscopy.

\begin{tabular}{|c|c|c|c|}
\hline Adsorbate or reactant & Material & Study & Ref \\
\hline Acetic acid & Rutile & Adsorption & {$[64]$} \\
\hline Acetate & Rutile & Adsorption & {$[65]$} \\
\hline Acrylic acid & P25 & Adsorption & {$[66]$} \\
\hline Poly(Acrylic acid) & Hematite & Adsorption & [67] \\
\hline L- $\alpha$-alanine & P25 & Adsorption & {$[68]$} \\
\hline \multirow[t]{2}{*}{ Amino acid } & $\mathrm{P} 25$ & Photo-Oxidation & [69] \\
\hline & $\mathrm{Au} / \mathrm{TiO}_{2}$ & & \\
\hline p-Arsanilic acid & Iron-(Oxyhydr)Oxides & Adsorption & {$[70],[71]$} \\
\hline Aspartic acid & $\mathrm{TiO}_{2}$ (synthesis) & Adsorption & {$[72]$} \\
\hline Benzoic acid / benzoate & Aluminum Hydroxide & Adsorption & [73] \\
\hline Boric acid & Hydrous Ferric Oxide & Adsorption & {$[74]$} \\
\hline \multirow[t]{6}{*}{ Catechol } & $\mathrm{P} 25$ & Photo-Oxidation & [75] \\
\hline & & Adsorption & [76] \\
\hline & $\mathrm{TiO}_{2}$ (synthesis) & Adsorption & [48] \\
\hline & $\mathrm{Cr}_{2} \mathrm{O}_{3}$ & Adsorption & \\
\hline & $\mathrm{MnO}_{2}$ & Adsorption & \\
\hline & $\mathrm{Fe}_{2} \mathrm{O}_{3}$ & Adsorption & \\
\hline 4-Chlorocatechol & P25 & Adsorption & [77] \\
\hline Citric acid & Rutile & Adsorption & {$[64]$} \\
\hline
\end{tabular}


Anatase

$m$-Cresol

$o$-Cresol

Cyclohexane

Cyclohexanone

Cysteine

Dextrin

Dicarboxylates

$\alpha$-hydroxydicarboxylates

Dihydroxyphenylalanine

Dimethylarsinic acid

E. Coli

Ethanol

Formic acid

Formate

Fumaric acid

Gallic acid

Glutamic acid

Glyoxylic acid

Isopropyl

Methylphosphonofluoridate

Lactic acid

Maleic acid

Malonate

Malonic acid

Nicotinic acid

Nitrate

$o$-Phthalic acid

Oxalate

Oxalic acid
P25

UV100

$\mathrm{TiO}_{2}$ (synthesis)

P25

Anatase

Fe(III)(hydr)oxides

Rutile

Iron-(Oxyhydr)Oxides

P25

$\mathrm{TiO}_{2}$ (synthesis)

Rutile

$\mathrm{TiO}_{2}$ (synthesis)

Rutile

Hematite

P25

$\mathrm{TiO}_{2}$ (synthesis)

P25

P25

P25

Hematite

Rutile

Anatase

$\mathrm{Au} / \mathrm{TiO}_{2}$ (synthesis)

P25

$\mathrm{TiO}_{2}$ (synthesis)

$\mathrm{Al}_{2} \mathrm{O}_{3}$

Hematite

Anatase

Rutile

Anatase

Rutile

Anatase
[78]

Adsorption

[76]

Adsorption

[33],[79]

Photo-Oxidation

Adsorption

[80]

Adsorption

[47]

Adsorption

Photo-Oxidation

[81]

Adsorption

Adsorption

Photo-Oxidation

Photo-Oxidation

[84]

Adsorption

Adsorption

Adsorption

Photo-Oxidation

Adsorption

Adsorption

Adsorption

Photo-Oxidation

Adsorption

Adsorption

Adsorption

Photo-Oxidation

[89]

[90]

Adsorption

Adsorption

Adsorption

Adsorption

Photo-Oxidation

Adsorption

[45] 


\begin{tabular}{|c|c|c|c|}
\hline \multirow[t]{2}{*}{ Phenol } & Anatase & Adsorption & [11] \\
\hline & P25 & Photo-Oxidation & [93] \\
\hline \multirow[t]{5}{*}{ 4,4'-Bis(2-sulfostyryl)biphenyl } & Rutile & Photo-Oxidation & [94] \\
\hline & Anatase & & \\
\hline & Hematite & & \\
\hline & $\delta$-Alumina & & \\
\hline & Lepidocrocite & & \\
\hline$\beta$-Picoline & $\mathrm{TiO}_{2}$ (synthesis) & Adsorption & {$[51]$} \\
\hline Polyacrylates & Hematite & Adsorption & [95] \\
\hline 1,2-propylene glycol & $\mathrm{P} 25$ & Photo-Oxidation & [93] \\
\hline Pyridine & $\mathrm{P} 25$ & Adsorption & [96] \\
\hline Pyruvic Acid & P25 & Adsorption & [66] \\
\hline \multirow[t]{2}{*}{ Pyridine-3-carbaldehyde } & $\mathrm{TiO}_{2}$ (synthesis) & adsorption & [97] \\
\hline & & & [51] \\
\hline Ru-bpy & $\mathrm{TiO}_{2}$ (synthesis) & Adsorption & {$[98]$} \\
\hline \multirow[t]{3}{*}{ Succinate } & Rutile & Adsorption & {$[58]$} \\
\hline & Anatase & & \\
\hline & Lepidocrocite & & \\
\hline \multirow[t]{2}{*}{ Succinic acid } & Hematite & Adsorption & {$[85]$} \\
\hline & P25 & Photo-Oxidation & [90] \\
\hline \multirow[t]{2}{*}{ Toluene } & $\mathrm{TiO}_{2}$ (synthesis) & Photo-Oxidation & [99] \\
\hline & $\mathrm{P} 25-\mathrm{TiO}_{2}$ & & {$[100]$} \\
\hline
\end{tabular}

Table 3. Selection of previously published ATR-FTIR studies concerning the adsorption and photooxidation of common ligands on metal oxides surfaces.

\section{Concluding remarks}

The ATR-FTIR technique offers the chance to obtain novel information concerning interfacial processes in situ. This information can be used to explain surface reaction mechanisms. Hence, ATR-FTIR studies are becoming increasingly popular as an investigative technique and may now be considered as one tool of choice in the field of interfacial chemistry when compared to other techniques, particularly in obtaining data under ambient conditions. This is due to the major advantages of ATR-FTIR spectroscopy such as the in situ data collection, as well as the high sensitivity, simplicity, and rapidity of the measurements.

The use of ATR-FTIR in the area of photocatalysis is of great importance since it provides both qualitative and quantitative molecular insight into interfacial processes occurring in the dark (adsorption) and under UV illumination (adsorption/desorption and chemical reactions). The information obtained will often be the key for a deeper understanding of the mechanisms occurring in metal oxide photocatalysis. 


\section{Acknowledgements}

The present study was performed within the project "Establishment of the Laboratory of Photoactive Nanocomposite Materials" (No. 14.750.31.0016) supported by a Grant from the Government of the Russian Federation. M. Faycal Atitar gratefully acknowledges a scholarship from the DAAD in the Frame of a Sandwich-Program.

\section{Author details}

Mohamed Faycal Atitar ${ }^{*}$, Hamza Belhadj ${ }^{1}$, Ralf Dillert $^{1}$ and Detlef W. Bahnemann ${ }^{1,2}$

*Address all correspondence to: bahnemann@iftc.uni-hannover.de

1 Institut fuer Technische Chemie, Leibniz UniversitaetHannover, Hannover, Germany

2 Laboratory of Photoactive Nanocomposite Materials, Department of Photonics, Faculty of Physics, Saint-Petersburg State University, Saint-Petersburg, Russia

\section{References}

[1] Hoffmann MR, Martin ST, Choi W, Bahnemann DW. Environmental Applications of Semiconductor Photocatalysis. Chemical Reviews 1995;95(1):69-96.

[2] Schneider J, Matsuoka M, Takeuchi M, Zhang J, Horiuchi Y, Anpo M, Bahnemann DW. Understanding $\mathrm{TiO}_{2}$ Photocatalysis: Mechanisms and Materials. Chemical Reviews 2014;114: 9919-9986.

[3] De Angelis F, Di Valentin C, Fantacci S, Vittadini A, Selloni A. Theoretical Studies on Anatase and Less Common $\mathrm{TiO}_{2}$ Phases: Bulk, Surfaces, and Nanomaterials. Chemical Reviews 2014;114(19):9708-9753.

[4] Linsebigler A, Lu G, Jr JY. Photocatalysis on $\mathrm{TiO}_{2}$ Surfaces: Principles, Mechanisms, and Selected Results. Chemical Reviews 1995;95:735-758.

[5] Hashimoto K, Irie H, Fujishima A. $\mathrm{TiO}_{2}$ Photocatalysis: A Historical Overview and Future Prospects. Japanese Journal of Applied Physics 2006;44(12):8269-8285.

[6] Diebold U. The Surface Science of Titanium Dioxide. Surface Science Reports 2003;48(5-8):53-229.

[7] Ismail AA, Bahnemann DW. Photochemical Splitting of Water for Hydrogen Production by Photocatalysis: A Review. Solar Energy Materials and Solar Cells 2014;128:85-101. 
[8] Henderson MA. A Surface Science Perspective on $\mathrm{TiO}_{2}$ Photocatalysis. Surface Science Reports 2011;66(6-7):185-297.

[9] Fujishima A, Zhang X, Tryk D. $\mathrm{TiO}_{2}$ Photocatalysis and Related Surface Phenomena. Surface Science Reports 2008;63(12):515-582.

[10] Montoya JF, Peral J, Salvador P. Comprehensive Kinetic and Mechanistic Analysis of $\mathrm{TiO}_{2}$ Photocatalytic Reactions According to the Direct-Indirect Model: (I) Theoretical Approach. Journal of Physical Chemistry C 2014;118(26):14266-14275.

[11] Montoya J, Atitar FM, Bahnemann DW, Peral J, and, Salvador P. Comprehensive Kinetic and Mechanistic Analysis of $\mathrm{TiO}_{2}$ Photocatalytic Reactions According to the Direct-Indirect (DI) Model: II) Experimental Validation. Journal of Physical Chemistry C 2014;118(28):14276-14290.

[12] Miranda PB, Shen YR. Liquid Interfaces: A Study by Sum-Frequency Vibrational Spectroscopy. Journal of Physical Chemistry B 1999;103(17):3292-307.

[13] Drevillon B. Spectroscopic Ellipsometry in the Infrared Range. Thin Solid Films 1998;313-314:625-630.

[14] Michael JW, Shouzhong Z, Ho YHC. The New Interfacial Ubiquity of Surface-Enhanced Raman Spectroscopy Analytical Chemistry 2000; 72: 38-47.

[15] McQuillan AJ. Probing Solid-Solution Interfacial Chemistry with ATR-IR Spectroscopy of Particle Films. Advanced Materials 2001;13(12-13):1034-1038.

[16] Simonescu C. Advanced Aspects of Spectroscopy. Akhyar Farrukh M (ed.). InTech 2012. ISBN: 978-953-51-0715-6. Available from : http://www.intechopen.com/books/ advanced-aspects-of-spectroscopy.

[17] Tejedor MI, Anderson MA. In Situ Attenuated Total Reflection Fourier Transform Infrared Studies of the Goethite (a-FeOOH)-Aqueous Solution Interface. Langmuir 1986;2(2):203-210.

[18] Hug S, Sulzberger B. In situ Fourier Transform Infrared Spectroscopic Evidence for the Formation of Several Different Surface Complexes of Oxalate on $\mathrm{TiO}_{2}$ in the Aqueous Phase. Langmuir 1994;18(12):3587-3597.

[19] Connor P, Dobson K, McQuillan AJ. New Sol-gel Attenuated Total Reflection Infrared Spectroscopic Method for Analysis of Adsorption at Metal Oxide Surfaces in Aqueous Solutions. Chelation of $\mathrm{TiO}_{2}, \mathrm{ZrO}_{2}$, and $\mathrm{Al}_{2} \mathrm{O}_{3}$ Surfaces by Catechol, 8-Quinolinol, and Acetylacetone. Langmuir 1995;(6):4193-4195.

[20] Roddick-Lanzilotta A, Connor P, McQuillan AJ. An In Situ Infrared Spectroscopic Study of the Adsorption of Lysine to $\mathrm{TiO}_{2}$ from an Aqueous Solution. Langmuir 1998;(17):6479-6484. 
[21] Roddick-Lanzilotta A, McQuillan AJ. An In Situ Infrared Spectroscopic Investigation of Lysine Peptide and Polylysine Adsorption to $\mathrm{TiO}_{2}$ from Aqueous Solutions. Journal of Colloid and Interface Science 1999;217(1):194-202.

[22] Beaussart A, Petrone L, Mierczynska-Vasilev A, McQuillan AJ, Beattie DA. In Situ ATR FTIR Study of Dextrin Adsorption on Anatase $\mathrm{TiO}_{2}$. Langmuir 2012;28(9):42334240 .

[23] Mendive CB, Bredow T, Blesa MA, Bahnemann DW. ATR-FTIR Measurements and Quantum Chemical Calculations Concerning the Adsorption and Photoreaction of Oxalic Acid on $\mathrm{TiO}_{2}$. Physical Chemistry Chemical Physics PCCP 2006;8(27):32323247.

[24] Mendive CB, Bredow T, Feldhoff A, Blesa MA, Bahnemann DW. Adsorption of Oxalate on Anatase (100) and Rutile (110) Surfaces in Aqueous Systems: Experimental Results vs. Theoretical Predictions. Physical Chemistry Chemical Physics 2009;11(11): 1794-1808.

[25] Stuart B. Infrared Spectroscopy: Fundamentals and Applications. Wiley 2004.

[26] Hind AR, Bhargava SK, McKinnon A. At the Solid/Liquid Interface: FTIR/ATR The Tool of Choice. Advances in Colloid and Interface Science 2001;93(1-3):91-114.

[27] Smith BC. Fundamentals of Fourrier Transform Infrared Spectroscopy (Second Edition). CRC Press Taylor \& Francis Group 2011.

[28] Harrick NJ. Surface Chemistry from Spectral Analysis of Totally Internally Reflected Radiation. Journal of Physical Chemistry 1960;64(9):1110-1114.

[29] Fahrenfort J. Attenuated Total Reflection: A New Principle for the Production of Useful Infrared Reflection Spectra of Organic Compounds. Spectrochimica Acta 1961;17(7):698-709.

[30] Mudunkotuwa IA, Al Minshid A, Grassian VH. ATR-FTIR Spectroscopy as a Tool to Probe Surface Adsorption on Nanoparticles at the Liquid-Solid Interface in Environmentally and Biologically Relevant Media. Analyst 2014;139(5):870-881.

[31] Khoshhesab ZM. Infrared Spectroscopy - Materials Science, Engineering and Technology. Theophile T (ed). InTech 2012. ISBN:978-953-51-0537-4. Available from: http://www.intechopen.com/books/infrared-spectroscopy-materials-science-engineering-and-technology/fundamental-of-reflectance-ir-spectroscopy

[32] Vigano C, Ruysschaert JM, Goormaghtigh E. Sensor Applications of Attenuated Total Reflection Infrared Spectroscopy. Talanta 2005;65(5):1132-1142.

[33] Almeida AR, Moulijn JA, Mul G. In Situ ATR-FTIR Study on the Selective Photo-oxidation of Cyclohexane over Anatase $\mathrm{TiO}_{2}$. Journal of Physical Chemistry C 2008;112(5):1552-1561. 
[34] Bourikas K, Kordulis C, Lycourghiotis A. Titanium Dioxide (Anatase and Rutile): Surface Chemistry, Liquid-Solid Interface Chemistry, and Scientific Synthesis of Supported Catalysts. Chemical Reviews 2014;114:9754-9823.

[35] Hodgson A, Haq S. Water Adsorption and the Wetting of Metal Surfaces. Surface Science Reports 2009;64(9):381-451.

[36] Henderson M. The Interaction of Water with Solid Surfaces: Fundamental Aspects Revisited. Surface Science Reports 2002;46(1-8):1-308.

[37] Mendive CB, Hansmann D, Bredow T, Bahnemann D. New Insights into the Mechanism of $\mathrm{TiO}_{2}$ Photocatalysis: Thermal Processes beyond the Electron-Hole Creation. Journal of Physical Chemistry C 2011;115(40):19676-85.

[38] Takeuchi M, Martra G, Coluccia S, Anpo M. Investigations of the Structure of $\mathrm{H}_{2} \mathrm{O}$ Clusters Adsorbed on $\mathrm{TiO}_{2}$ Surfaces by Near-Infrared Absorption Spectroscopy. Journal of Physical Chemistry B 2005;109(15):7387-7391.

[39] Warren D, McQuillan AJ. Influence of Adsorbed Water on Phonon and UV-Induced IR Absorptions of $\mathrm{TiO}_{2}$ Photocatalytic Particle Films. Journal of Physical Chemistry B 2004;19373-19379.

[40] Almeida AR, Calatayud M, Tielens F, Moulijn JA, Mul G. Combined ATR-FTIR and DFT Study of Cyclohexanone Adsorption on Hydrated $\mathrm{TiO}_{2}$ Anatase Surfaces. Journal of Physical Chemistry C 2011;115(29):14164-14172.

[41] Li G, Li L, Boerio-Goates J, Woodfield BF. High Purity Anatase $\mathrm{TiO}_{2}$ Nanocrystals: Near Room-Temperature Synthesis, Grain Growth Kinetics, and Surface Hydration Chemistry. Journal of American Chemical Society 2005;127(24):8659-8666.

[42] Rubasinghege G, Grassian VH. Role(s) of Adsorbed Water in the Surface Chemistry of Environmental Interfaces. Chemical Communications (Cambridge) 2013;49(30): 3071-3094.

[43] Uosaki K, Yano T, Nihonyanagi S. Interfacial Water Structure at As-prepared and UV-induced Hydrophilic $\mathrm{TiO}_{2}$ Surfaces Studied by Sum Frequency Generation Spectroscopy and Quartz Crystal Microbalance. Journal of Physical Chemistry B 2004;108(50):19086-19088.

[44] Sakai N, Fujishima A, Watanabe T, Hashimoto K. Quantitative Evaluation of the Photoinduced Hydrophilic Conversion Properties of $\mathrm{TiO}_{2}$ Thin Film Surfaces by the Reciprocal of Contact Angle. Journal of Physical Chemistry B 2003;107(4):1028-1035.

[45] Young AG, McQuillan AJ. Adsorption/Desorption Kinetics from ATR-IR Spectroscopy. Aqueous Oxalic Acid on Anatase $\mathrm{TiO}_{2}$. Langmuir 2009;25(6):3538-3548.

[46] Dobson KD, McQuillan AJ. In Situ Infrared Spectroscopic Analysis of the Adsorption of Aliphatic Carboxylic Acids to $\mathrm{TiO}_{2}, \mathrm{ZrO}_{2}, \mathrm{Al}_{2} \mathrm{O}_{3}$, and $\mathrm{Ta}_{2} \mathrm{O}_{5}$ from Aqueous Solu- 
tions. Spectrochimica Acta Part A Molecular and Biomolecular Spectroscopy 1999;55(7-8):1395-1405.

[47] Begonja S, Rodenas L, Borghi EB, Morando PJ. Adsorption of Cysteine on $\mathrm{TiO}_{2}$ at Different $\mathrm{pH}$ Values: Surface Complexes Characterization by FTIR-ATR and Langmuir Isotherms Analysis. Colloids and Surfaces A: Physicochemical and Engineering Aspects 2012;403:114-120.

[48] Gulley-Stahl H, Hogan PA, Schmidt WL, Wall SJ, Buhrlage A, Bullen HA. Surface Complexation of Catechol to Metal Oxides: An ATR-FTIR, Adsorption, and Dissolution Study. Environmental Science and Technology 2010;44(11):4116-4121.

[49] Popova G. In Situ FTIR Study of Pyridine-3-carbaldehyde Adsorption on $\mathrm{TiO}_{2}$ (Anatase) and V-Ti-O Catalyst. Reaction Kinetics and Catalysis Letters 2004;83(2):353-360.

[50] Chernobay GB, Chesalov YA, Baltakhinov VP, Popova GY, Andrushkevich TV. In Situ FTIR Study of $\beta$-picoline Transformations on V-Ti-O Catalysts. Catalysis Today 2011;164(1):58-61.

[51] Chesalov YA, Chernobay GB, Andrushkevich TV. FTIR Study of the Surface Complexes of $\beta$-picoline, 3-pyridine-carbaldehyde and Nicotinic acid on Sulfated $\mathrm{TiO}_{2}$ (Anatase). Journal of Molecular Catalysis A: Chemical 2013;373:96-107.

[52] Koczoń P, Dobrowolski JC, Lewandowski W, Mazurek AP. Experimental and Theoretical IR and Raman Spectra of Picolinic, Nicotinic and Isonicotinic Acids. Journal of Molecular Structure 2003;655(1):89-95.

[53] Nakamoto K. Infrared and Raman Spectra of Inorganic and Coordination Compounds: Part B: Applications in Coordination, Organometallic, and Bioinorganic Chemistry. 6th edition. Wiley 2008.

[54] Atitar MF, Dillert R, Bahnemann DW. An In Situ ATR-FTIR Study of the Adsorption of Imazapyr Herbicide onto $\mathrm{TiO}_{2}$ Surface. Unpublished Results.

[55] Nanayakkara CE, Dillon JK, Grassian VH. Surface Adsorption and Photochemistry of Gas-Phase Formic Acid on $\mathrm{TiO}_{2}$ Nanoparticles: The Role of Adsorbed Water in Surface Coordination, Adsorption Kinetics, and Rate of Photoproduct Formation. Journal of Physical Chemistry C 2014;118(44):25487-25495.

[56] Petrone L, McQuillan AJ. Alginate Ion Adsorption on a $\mathrm{TiO}_{2}$ Particle Film and Interactions of Adsorbed Alginate with Calcium Ions Investigated by Attenuated Total Reflection Infrared (ATR-IR) Spectroscopy. Applied Spectroscopy 2011;65(10):11621169.

[57] Qu Q, Geng H, Peng R, Cui Q, Gu X, Li F, Wang M. Chemically Binding Carboxylic Acids onto $\mathrm{TiO}_{2}$ Nanoparticles with Adjustable Coverage by Solvothermal Strategy. Langmuir 2010;26(12):9539-46.

[58] Hug SJ, Bahnemann DW. Infrared Spectra of Oxalate, Malonate and Succinate Adsorbed on the Aqueous Surface of Rutile, Anatase and Lepidocrocite Measured with In 
Situ ATR-FTIR. Journal of Electron Spectroscopy and Related Phenomena 2006;150(2-3):208-219.

[59] Vittadini A, Selloni A, Rotzinger FP, Grätzel M. Formic Acid Adsorption on Dry and Hydrated $\mathrm{TiO}_{2}$ Anatase (101) Surfaces by DFT Calculations. Journal of Physical Chemistry B 2000;104(101):1300-1306.

[60] Mendive CB, Blesa MA, Bahnemann DW. The Adsorption and Photodegradation of Oxalic Acid at the $\mathrm{TiO}_{2}$ Surface. Water Science and Technology 2005;55(12):139-145.

[61] Mendive CB, Bredow T, Schneider J, Blesa M, Bahnemann DW. Oxalic Acid at the $\mathrm{TiO}_{2} /$ Water Interface under UV(A) Illumination: Surface Reaction Mechanisms. Journal of Catalysis 2015;322:60-72.

[62] Mendive CB, Bahnemann DW, Blesa MA. Microscopic Characterization of the Photocatalytic Oxidation of Oxalic Acid Adsorbed onto $\mathrm{TiO}_{2}$ by FTIR-ATR. Catalysis Today 2005;101(3-4):237-244.

[63] Mendive CB, Bredow T, Feldhoff A, Blesa MA, Bahnemann DW. Adsorption of Oxalate on Rutile Particles in Aqueous Solutions: A Spectroscopic, Electron-Microscopic and Theoretical Study. Physical Chemistry Chemical Physics PCCP 2008;10:19601974.

[64] Ojamäe L, Aulin C, Pedersen H, Käll P-O. IR and Quantum-Chemical Studies of Carboxylic Acid and Glycine Adsorption on Rutile $\mathrm{TiO}_{2}$ Nanoparticles. Journal of Colloid and Interface Science 2006;296(1):71-78.

[65] Rotzinger FP, Kesselman-Truttmann JM, Hug SJ, Shklover V, Grätzel M. Structure and Vibrational Spectrum of Formate and Acetate Adsorbed from Aqueous Solution onto the $\mathrm{TiO}_{2}$ Rutile (110) Surface. Journal of Physical Chemistry B 2004;108(16):50045017.

[66] Chen Y, Lin Y-F, Peng Z, Lin J. Transmission FT-IR Study on the Adsorption and Reactions of Lactic Acid and Poly(lactic Acid) on $\mathrm{TiO}_{2}$. Journal of Physical Chemistry C 2010;114(41):17720-17727.

[67] Kirwan LJ, Fawell PD, Van Bronswijk W. In Situ FTIR-ATR Examination of Poly(acrylic Acid) Adsorbed onto Hematite at Low pH. Langmuir 2003;19(14):58025807.

[68] Martra G, Horikoshi S, Anpo M, Coluccia S, Hidaka H. FTIR Study of Adsorption and Photodegradation of L- $\alpha$-alanine on $\mathrm{TiO}_{2}$ Powder. Research on Chemical Intermediates 2002;28(4):359-371.

[69] Dolamic I, Burgi T. In Situ ATR-IR Study on the Photocatalytic Decomposition of Amino Acids over $\mathrm{Au} / \mathrm{TiO}_{2}$ and $\mathrm{TiO}_{2}$. Journal of Physical Chemistry C 2011;115(5): 2228-2234.

[70] Mitchell W, Goldberg S, Al-Abadleh HA. In Situ ATR-FTIR and Surface Complexation Modeling Studies on the Adsorption of Dimethylarsinic Acid and p-Arsanilic 
Acid on Iron-(oxyhydr)Oxides. Journal of Colloid and Interface Science 2011;358(2): 534-540.

[71] Depalma S, Cowen S, Hoang T, Al-Abadleh HA. Adsorption Thermodynamics of pArsanilic Acid on Iron (Oxyhydr)Oxides: In-Situ ATR-FTIR Studies. Environmental Science and Technology 2008;42(6):1922-1927.

[72] Roddick-Lanzilotta A, McQuillan AJ. An In Situ Infrared Spectroscopic Study of Glutamic Acid and of Aspartic Acid Adsorbed on $\mathrm{TiO}_{2}$ : Implications for the Biocompatibility of Titanium. Journal of Colloid and Interface Science 2000;227(1):48-54.

[73] Guan X, Chen G, Shang C. ATR-FTIR and XPS Study on the Structure of Complexes Formed upon the Adsorption of Simple Organic Acids on Aluminum Hydroxide. Journal of Environmental Science 2007;19(4):438-443.

[74] Peak D, Luther GW, Sparks DL. ATR-FTIR Spectroscopic Studies of Boric Acid Adsorption on Hydrous Ferric Oxide. Geochimica et Cosmochimica Acta 2003;67(14): 2551-2560.

[75] Araujo PZ, Mendive CB, Rodenas LA. G, Morando PJ, Regazzoni AE, Blesa MA, Bahnemann DW. FT-IR-ATR as a Tool to Probe Photocatalytic Interfaces. Colloids and Surfaces A: Physicochemical and Engineering Aspects 2005;265(1-3):73-80.

[76] Araña J, Pulido Melián E, Rodríguez López VM, Peña Alonso A, Doña Rodríguez JM, González Díaz O, Perez Pena J. Photocatalytic Degradation of Phenol and Phenolic Compounds Part I. Adsorption and FTIR Study. Journal of Hazardous Materials 2007;146(3):520-528.

[77] Martin ST, Kesselman JM, Park DS, Lewis NS, Hoffmann MR. Surface Structures of 4-Chlorocatechol Adsorbed on Titanium Dioxide. Environmental Science and Technology 1996;30(8):2535-2542.

[78] Mudunkotuwa IA, Grassian VH. Citric Acid Adsorption on $\mathrm{TiO}_{2}$ Nanoparticles in Aqueous Suspensions at Acidic and Circumneutral pH: Surface Coverage, Surface Speciation, and Its Impact on Nanoparticle-Nanoparticle Interactions. Journal of American Chemical Society. 2010;132(42):14986-14994.

[79] Hernández-Alonso MD, Almeida AR, Moulijn JA, Mul G. Identification of the Role of Surface Acidity in the Deactivation of $\mathrm{TiO}_{2}$ in the Selective Photo-Oxidation of Cyclohexane. Catalysis Today 2009;143(3-4):326-333.

[80] Almeida A, Moulijn J, Mul G. Photocatalytic Oxidation of Cyclohexane over $\mathrm{TiO}_{2}$ : Evidence for a Mars-Van Krevelen Mechanism. Journal of Physical Chemistry C 2011;1330-1338.

[81] Borer P, Hug SJ. Photo-Redox Reactions of Dicarboxylates and $\alpha$-Hydroxydicarboxylates at the Surface of Fe(III)(hydr)Oxides Followed with in Situ ATR-FTIR Spectroscopy. Journal of Colloid and Interface Science 2014;416:44-53. 
[82] Bahri S, Jonsson CM, Jonsson CL, Azzolini D, Sverjensky DA, Hazen RM. Adsorption and Surface Complexation Study of L-DOPA on Rutile $\left(\alpha-\mathrm{TiO}_{2}\right)$ in NaCl Solutions. Environmental Science and Technology 2011;45(9):3959-3966.

[83] Nadtochenko VA, Rincon AG, Stanca SE, Kiwi J. Dynamics of E.coli Membrane Cell Peroxidation During $\mathrm{TiO}_{2}$ Photocatalysis Studied by ATR-FTIR Spectroscopy and AFM Microscopy. Journal of Photochemical and Photobiological Science A Chemistry 2005;169(2):131-137.

[84] Tan J, Yang L, Kang Q, Cai Q. In Situ ATR-FTIR and UV-Visible Spectroscopy Study of Photocatalytic Oxidation of Ethanol over $\mathrm{TiO}_{2}$ Nanotubes. Analytical Letters 2011;44(6):1114-1125.

[85] Hwang YS, Lenhart JJ. Adsorption of C4-dicarboxylic Acids at the Hematite/Water Interface. Langmuir 2008;24(24):13934-13943.

[86] Araujo PZ, Morando PJ, Martínez E, Blesa MA. Time Evolution of Surface Speciation During Heterogeneous Photocatalysis: Gallic Acid on Titanium Dioxide. Applied Catalysis B Environmental 2012;125:215-221.

[87] Ekström GN, McQuillan AJ. In Situ Infrared Spectroscopy of Glyoxylic Acid Adsorption and Photocatalysis on $\mathrm{TiO}_{2}$ in Aqueous Solution. Journal of Physical Chemistry B 1999;103(48):10562-10565.

[88] Hirakawa T, Sato K, Komano A, Kishi S, Nishimoto CK, Mera N, Kugishima M, Sano T, Ichinose H, Negishi N, Seto Y, Takeuchi K. Experimental Study on Adsorption and Photocatalytic Decomposition of Isopropyl Methylphosphonofluoridate at Surface of $\mathrm{TiO}_{2}$ Photocatalyst. Journal of Physical Chemistry C 2010;114(5):2305-2314.

[89] Hu X, Burgi T. Photoinduced Electron Transfer and Photodegradation of Malonic Acid at $\mathrm{Au} / \mathrm{TiO}_{2}$ Investigated by In Situ ATR-IR Spectroscopy. Applied Catalysis A General 2012;449:139-144.

[90] Dolamic I, Burgi T. Photocatalysis of Dicarboxylic Acids over $\mathrm{TiO}_{2}$ : An In Situ ATRIR Study. Journal of Catalysis 2007;248(2):268-276.

[91] Baltrusaitis J, Schuttlefield J, Jensen JH, Grassian VH. FTIR Spectroscopy Combined with Quantum Chemical Calculations to Investigate Adsorbed Nitrate on Aluminium Oxide Surfaces in the Presence and Absence of Co-adsorbed Water. Physical Chemistry Chemical Physics PCCP 2007;9(36):4970-4980.

[92] Hwang YS, Liu J, Lenhart JJ, Hadad CM. Surface Complexes of Phthalic Acid at the Hematite/Water Interface. Journal of Colloid and Interface Science 2007;307(1):124134.

[93] Araña J, Tello Rendón E, Doña Rodríguez JM, Herrera Melián JA, González Díaz O, Pérez Peña J. High Concentrated Phenol and 1,2-propylene Glycol Water Solutions Treatment by Photocatalysis. Applied Catalysis B Environmental 2001;30(1-2):1-10. 
[94] Kesselman-Truttmann JM, Hug SJ. Photodegradation of 4,4'-Bis(2-sulfostyryl)biphenyl (DSBP) on Metal Oxides Followed by In Situ ATR-FTIR Spectroscopy. Environmental Science and Technology 1999;33(18):3171-3176.

[95] Bronswijk W Van, Kirwan LJ, Fawell PD. In Situ Adsorption Densities of Polyacrylates on Hematite Nano-particle Films as Determined by ATR-FTIR Spectroscopy. Vibrational Spectroscopy 2006;41(2):176-181.

[96] Green IX, Buda C, Zhang Z, Neurock M, Yates JT. IR Spectroscopic Measurement of Diffusion Kinetics of Chemisorbed Pyridine through $\mathrm{TiO}_{2}$ Particles. Journal of Physical Chemistry C 2010;114(39):16649-16659.

[97] Popova GY, Chesalov YA, Andrushkevich TV. In situ FTIR Study of Pyridine-3-carbaldehyde Adsorption on $\mathrm{TiO}_{2}$ (Anatase) and V-Ti-O Catalyst. Reaction Kinetics and Catalysis Letters. 2004;83(2):353-360.

[98] Pe C, Kador L, Peng B, Thelakkat M. Characterization of the Adsorption of Ru-bpy Dyes on Mesoporous $\mathrm{TiO}_{2}$ Films with UV - Vis, Raman, and FTIR Spectroscopies. Journal of Physical Chemistry B 2006;110(17):8723-8730.

[99] Maira A, Coronado J, Augugliaro V, Yeung K, Conesa J, Soria J. Fourier Transform Infrared Study of the Performance of Nanostructured $\mathrm{TiO}_{2}$ Particles for the Photocatalytic Oxidation of Gaseous Toluene. Journal of Catalysis 2001;202(2):413-420.

[100] Lin H, Long J, Gu Q, Zhang W, Ruan R, Li Z, Wang X. In Situ IR Study of Surface Hydroxyl Species of Dehydrated $\mathrm{TiO}_{2}$ : Towards Understanding Pivotal Surface Processes of $\mathrm{TiO}_{2}$ Photocatalytic Oxidation of Toluene. Physical Chemistry Chemical Physics 2012;14(26):9468-9474. 
